ARTICLE

\title{
Anomalous fractionation of mercury isotopes in the Late Archean atmosphere
}

\author{
Aubrey L. Zerkle (1) ${ }^{1,7 凶}$, Runsheng Yin ${ }^{2,7 凶}$, Chaoyue Chen ${ }^{3}$, Xiangdong Li (i) ${ }^{4}$, Gareth J. Izon (iD) ${ }^{1,6}$ \& \\ Stephen E. Grasby ${ }^{5}$
}

Earth's surface underwent a dramatic transition 2.3 billion years ago when atmospheric oxygen first accumulated during the Great Oxidation Event, but the detailed composition of the reducing early atmosphere is not well known. Here we develop mercury $(\mathrm{Hg})$ stable isotopes as a proxy for paleoatmospheric chemistry and use $\mathrm{Hg}$ isotope data from 2.5 billionyear-old sedimentary rocks to examine changes in the Late Archean atmosphere immediately prior to the Great Oxidation Event. These sediments preserve evidence of strong photochemical transformations of mercury in the absence of molecular oxygen. In addition, these geochemical records combined with previously published multi-proxy data support a vital role for methane in Earth's early atmosphere.

\footnotetext{
${ }^{1}$ School of Earth and Environmental Sciences and Centre for Exoplanet Science, University of St Andrews, St Andrews, Fife KY16 9 AL Scotland, UK. ${ }^{2}$ State Key Laboratory of Ore Deposit Geochemistry, Institute of Geochemistry, Chinese Academy of Sciences, Guiyang 550081, China. ${ }^{3}$ State Key Laboratory of Environmental Geochemistry, Institute of Geochemistry, Chinese Academy of Sciences, Guiyang 550081, China. ${ }^{4}$ Department of Civil and Environmental Engineering, The Hong Kong Polytechnic University, Hung Hom, Kowloon, Hong Kong. ${ }^{5}$ Geological Survey of Canada, Calgary Natural Resources Canada, 3303 33rd Street NW, Calgary, AB T2L 2A7, Canada. ${ }^{6}$ Present address: Department of Earth, Atmospheric \& Planetary Sciences, Massachusetts Institute of Technology, Cambridge, MA, USA. ${ }^{7}$ These authors contributed equally: Aubrey L. Zerkle, Runsheng Yin. ${ }^{凶}$ email: az29@st-andrews.ac.uk; yinrunsheng@mail.gyig.ac.cn
} 


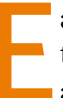
arth's atmosphere has undergone significant changes during the 4.5 billion-year history of the planet, from fully anoxic and reducing in the Archean to the oxygen-rich atmosphere of today. Molecular oxygen is thought to have first become abundant in Earth's atmosphere during the Great Oxidation Event (GOE), some $\sim 2.3$ billion years ago $(\mathrm{Ga})^{1,2}$. However, recent evidence indicates that this change may not have been unidirectional $^{3,4}$ and that dynamic atmospheric transitions could have occurred prior to the $\mathrm{GOE}^{5,6}$.

The utility of individual geochemical proxies for determining the composition of the atmosphere is limited, since most redox proxies reflect oceanic conditions ${ }^{7}$ or are only indirectly tied to atmospheric chemistry through an inferred connection with oxidative weathering ${ }^{5,8}$. Currently, the only geochemical proxy that can provide direct constraints on atmospheric chemistry under reducing conditions is that of the four stable isotopes of sulfur $\left({ }^{32} \mathrm{~S},{ }^{33} \mathrm{~S},{ }^{34} \mathrm{~S}\right.$, and $\left.{ }^{36} \mathrm{~S}\right)$. The sulfur isotope record of sedimentary sulfides and sulfates prior to $\sim 2.3 \mathrm{Ga}$ is characterized by large magnitude $\Delta^{33} \mathrm{~S}$ and $\Delta^{36} \mathrm{~S}$ values which represent $\mathrm{S}$ isotope compositions that deviate significantly from those produced during the majority of chemical and biological processes ${ }^{1}$. The preservation of these $S$ isotope signals, termed sulfur massindependent fractionation (S-MIF), in Archean and earliest Proterozoic rocks is considered to be the strongest line of continuous evidence for low oxygen levels in the Earth's early atmosphere $\left(<10^{-5}\right.$ times present atmospheric levels $\left.{ }^{9}\right)$. This is because low oxygen levels are a prerequisite for the production of S-MIF in the atmosphere, the transfer of the S-MIF to Earth's surface, and the preservation of S-MIF in the geologic record. Despite the importance of S-MIF in providing upper limits on atmospheric oxygen levels, significant uncertainties remain about the specific reactions that generate this signal and how they respond in reducing atmospheres.

Mercury has seven stable isotopes $\left({ }^{196} \mathrm{Hg},{ }^{198} \mathrm{Hg},{ }^{199} \mathrm{Hg},{ }^{200} \mathrm{Hg}\right.$, ${ }^{201} \mathrm{Hg},{ }^{202} \mathrm{Hg}$, and ${ }^{204} \mathrm{Hg}$ ) that are fractionated in the environment by both mass-dependent ( $\mathrm{Hg}-\mathrm{MDF}$, denoted as $\delta^{202} \mathrm{Hg}$ ) and mass-independent ( $\mathrm{Hg}-\mathrm{MIF}$, denoted as $\Delta^{199} \mathrm{Hg}, \Delta^{200} \mathrm{Hg}$, and $\Delta^{201} \mathrm{Hg}$ ) processes. Like sulfur, the atmosphere and oceans play critical roles in the global cycling of $\mathrm{Hg}$. In the modern $\mathrm{Hg}$ cycle, gaseous $\mathrm{Hg}(0)$ represents $>90 \%$ of the atmospheric $\mathrm{Hg}$ pool and has sufficiently long atmospheric residence time (0.5-2 years) for global transport ${ }^{10}$. Gaseous $\mathrm{Hg}(0)$ can be removed from the atmosphere through transformation to gaseous oxidized $\mathrm{Hg}$ (II) species, which are particle reactive and soluble, and thus more easily deposited through wet and dry deposition; or through direct uptake by vegetation and adsorption by soils, followed by oxidation to $\mathrm{Hg}$ (II) $)^{11-13}$. Mercury undergoes complex cycling between the atmosphere, land, and ocean, but its ultimate burial is typically to ocean sediments (e.g., as reviewed in ref. ${ }^{14}$ ).

Mercury isotopes have been shown to be a useful tracer in constraining changes in the sources and cycling of $\mathrm{Hg}$ in Earth history, especially during mass extinction events ${ }^{11,15-18}$. Hg-MDF occurs during the majority of biogeochemical $\mathrm{Hg}$ cycling processes, but Hg-MIF in natural environments is primarily associated with photochemical processes in the atmosphere and surface waters ${ }^{19-21}$. MIF-bearing $\mathrm{Hg}$ deposited in the oceans complexes with organic matter and sulfur ligands, and can be preserved in sediments, where these signatures appear to be largely resistant to postdepositional alteration ${ }^{11,15-17,22}$. Hg-MIF preserved in sediments spanning Earth history can therefore provide insight into $\mathrm{Hg}$ cycling processes, particularly in the Precambrian in the absence of a significant terrestrial biosphere (e.g., ref. ${ }^{23}$ ). Prior to the evolution of land plants, continents lacked significant terrestrial vegetation and soil development, such that volcanic $\mathrm{Hg}(0)$ would have been the sole source of $\mathrm{Hg}$ to the atmosphere ${ }^{22}$, and $\mathrm{Hg}$ cycling would have been largely controlled by abiotic transformations between the atmosphere and oceans. The lack of oxygen in the Archean atmosphere and ocean would have resulted in significantly different atmospheric reactions and burial of $\mathrm{Hg}$ in sediments as well. However, to date no detailed study of $\mathrm{Hg}$ isotopes has been conducted to examine the cycling of $\mathrm{Hg}$ and manifestation of $\mathrm{Hg}$-MIF signals in Archean sediments. Here we use Hg-MIF data from Late Archean sediments to provide important constraints on $\mathrm{Hg}$ cycling and atmospheric chemistry in the immediate run-up to the GOE. These sediments preserve evidence of strong atmospheric transformations of $\mathrm{Hg}$ in an anoxic atmosphere. Combined with previous records of S-MIF, changes in $\mathrm{Hg}$-MIF also support an important role for methane and hydrocarbon haze formation in the Late Archean atmosphere.

\section{Results and discussion}

Hg isotopes in Late Archean sediments. We studied sediments from the lower part of the Upper Nauga Formation, sampled from core GKF01 drilled by the Agouron Institute in the Griqualand West Basin, South Africa ${ }^{24}$ (SI, Supplementary Fig. 1). The core consists mainly of mudstones and dolostones deposited in a deep water slope environment of the CambellrandMalmani carbonate platform, as described in detail by Schröder et al. ${ }^{24}$ (Supplementary Fig. 2). Precise U-Pb zircon ages from associated volcani-clastic sediments place the base of the core at $\sim 2.65 \pm 0.08 \mathrm{Gyr}$ ago and the top of the core (within the Upper Nauga) at $\sim 2.5 \mathrm{Gyr} \mathrm{ago}^{25}$. Our interval of study spans several mudstone-dominated lithologies of the Upper Nauga Fm (Fig. 1). These and other mudstones within the Upper Nauga Fm have been interpreted to represent deep subtidal sediments deposited below storm weather wave base, and generally associated with basinal deepening and/or higher input of fine-grained detritus ${ }^{24}$. The GKF01 core has previously been the focus of extensive geological and geochemical characterization, including highresolution $\mathrm{Fe}$ speciation and S-MIF analyses (Supplementary Fig. 2) $6,24,26$.

Across an interval from $\sim 840$ to $830 \mathrm{~m}$ in the core, mercury concentrations rise from $\leq 10 \mathrm{ppb}$ to an average of $183 \mathrm{ppb}$, in association with an increase in total organic carbon (TOC) (Fig. 1; Supplementary Data 1). High levels of sedimentary $\mathrm{Hg}$ above the average shale values $\left(>62 \mathrm{ppb}^{22}\right)$ could be due to either increased input of $\mathrm{Hg}$ to the basin or to increased burial efficiency of $\mathrm{Hg}$ into the sediments. $\mathrm{Hg}$ in the modern oceans has a high affinity for both organic matter and organic sulfur ligands (thiols). The $\mathrm{Hg}$ content in these rocks shows no correlation with total sulfur content (Fig. 2a), and previously published paleoredox data show no evidence for euxinic depositional conditions in this interval (Supplementary Fig. 2; ref. 6,26), discounting enhanced scavenging by sulfur ligands as a cause for increased $\mathrm{Hg}$ burial. Instead, the $\mathrm{Hg}$ content in these rocks is positively correlated with wt\% TOC (Fig. 2b), although the Hg/TOC values show no systematic trends through the study interval (Fig. 1). Since volcanic emissions commonly (though not always) shift $\mathrm{Hg} / \mathrm{TOC}$ ratios in sediments ${ }^{22}$, these data might indicate that changes in $\mathrm{Hg}$ concentrations throughout this section are dominantly controlled by variations in TOC rather than volcanic input. In contrast, three samples exhibit very high $\mathrm{Hg}$ concentrations (with $\mathrm{Hg}>$ $1100 \mathrm{ppb}$ ) and correspondingly large spikes in $\mathrm{Hg} / \mathrm{TOC}$ ratios (Fig. 1), consistent with a major influx of $\mathrm{Hg}$ from an external source, such as increased volcanic activity ${ }^{22}$. We explore the implications of a volcanic $\mathrm{Hg}$ source on $\mathrm{Hg}$ isotope trends in the discussion below.

$\mathrm{Hg}$-MDF provides limited constraints on $\mathrm{Hg}$ cycling throughout this time period. We measure $\delta^{202} \mathrm{Hg}$ values from -1.9 to 


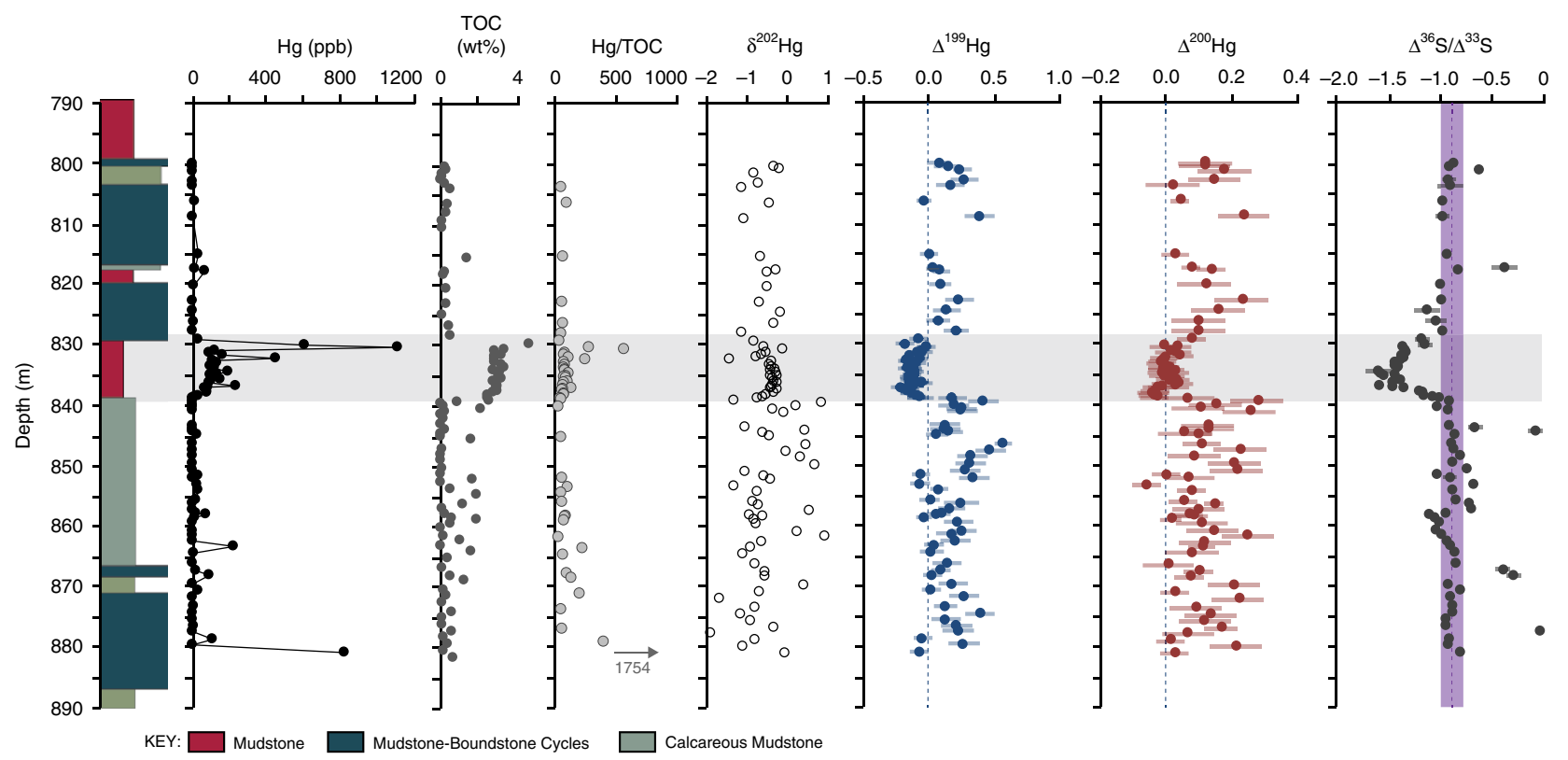

Fig. 1 Lithologic and geochemical data for the studied section. Data are listed in Supplementary Data 1, and include Hg concentrations (ppb), total organic carbon (TOC, wt\%), $\mathrm{Hg} / \mathrm{TOC}$ ratios for samples with TOC $>0.2 \mathrm{wt} \%(\mathrm{ppb} / \mathrm{wt} \%), \mathrm{Hg}$ isotope values $\left(\delta^{202} \mathrm{Hg}, \Delta^{199} \mathrm{Hg}\right.$, and $\Delta^{200} \mathrm{Hg}$, in \%o), and pyrite SMIF data $\left(\Delta^{36} \mathrm{~S} / \Delta^{33} \mathrm{~S}\right.$; from ref. ${ }^{26}$ ). Uncertainties on $\mathrm{Hg}$ isotope data correspond to the larger value of either the measurement uncertainty of replicate digests of MESS-2 or the uncertainty of repeated measurements of UM-Almadén. Uncertainty on $\Delta^{36} \mathrm{~S} / \Delta^{33} \mathrm{~S}$ was computed from the larger of the internal or external uncertainties associated with the raw $\Delta^{33} S$ and $\Delta^{36} S$ data (as previously reported ${ }^{26}$ ). Analytical uncertainties for additional data are encompassed within each individual data point. The gray shaded area indicates the interval where changes in $\Delta^{36} \mathrm{~S} / \Delta^{33} \mathrm{~S}$ correspond to changes in $\mathrm{Hg}$-MIF values; the vertical purple line illustrates the background Archean $\Delta^{36} \mathrm{~S} / \Delta^{33} \mathrm{~S}$ ratio; vertical dashed lines also illustrate $0 \%$ in $\Delta^{199} \mathrm{Hg}$ and $\Delta^{200} \mathrm{Hg}$.

$+0.9 \%$ (Fig. 1) in this section, spanning the range of $\delta^{202} \mathrm{Hg}$ values previously reported for marine sediments $(-2.5$ to $1 \%$; ref. ${ }^{20,22}$ ). However, $\delta^{202} \mathrm{Hg}$ alone is generally insufficient to identify specific sources and $\mathrm{Hg}$ cycling reactions, because $\mathrm{Hg}$ MDF is ubiquitous and occurs during all biological reactions (e.g., reduction, methylation, and demethylation), abiotic reactions (e.g., chemical reduction, photoreduction, and oxidation), and physical processes (e.g., volatilization, evaporation, adsorption, and dissolution) (as reviewed by ref. 20,27,28). Equilibrium partitioning and speciation can also cause significant Hg-MDF in natural samples (as reviewed by ref. 20,27,28), further complicating interpretations of sedimentary $\delta^{202} \mathrm{Hg}$ values. Since we lack a complete understanding of all the Hg-MDF processes in the Late Archean ocean and atmosphere, it is therefore difficult to interpret the variations of $\delta^{202} \mathrm{Hg}$ further in this study (as in previous studies ${ }^{15,23}$ ).

In contrast, $\mathrm{Hg}$-MIF provides more clear constraints on $\mathrm{Hg}$ cycling in the Archean, as it mainly occurs during photochemical processes with little contribution from complex biogeochemical cycling. Notably, significant changes in Hg-MIF occur throughout this section, for both odd- and even-number $\mathrm{Hg}$ isotopes (Fig. 1). We observe significant odd-number Hg-MIF, with $\Delta^{199} \mathrm{Hg}$ values from -0.2 to $0.6 \%$ (Fig. 1) and a $\Delta^{199} \mathrm{Hg} / \Delta^{201} \mathrm{Hg}$ ratio of $\approx 1$ (Fig. 2c). MIF of odd-number $\mathrm{Hg}$ isotopes, with $\Delta^{199} \mathrm{Hg} / \Delta^{201} \mathrm{Hg}$ ratios $\approx 1$, has previously been observed in various geochemical pools near Earth's surface (see ${ }^{20}$ and references therein), in samples mainly consisting of inorganic $\mathrm{Hg}$ species (Supplementary Fig. 3), and this signature has been attributed to the photoreduction of aqueous $\mathrm{Hg}(\mathrm{II})$ to $\mathrm{Hg}(0)^{19}$. Aqueous $\mathrm{Hg}$ (II) photoreduction produces negative $\Delta^{199} \mathrm{Hg}$ and $\Delta^{201} \mathrm{Hg}$ values in the product $\mathrm{Hg}(0)$, and positive $\Delta^{199} \mathrm{Hg}$ and $\Delta^{201} \mathrm{Hg}$ values in the residual $\mathrm{Hg}$ (II). Modeling studies suggest that $\mathrm{Hg}(\mathrm{II})$ photoreduction occurring in surface waters and aerosols plays an important role in generating odd-number Hg-MIF in natural samples ${ }^{29,30}$. Rain and seawater samples ${ }^{31-35}$, which mainly contain $\mathrm{Hg}(\mathrm{II})$ species, are characterized by positive odd-number Hg-MIF, whereas terrestrial reservoirs (e.g., plants and soils) that primarily accumulate $\mathrm{Hg}(0)$ are characterized by negative odd-number Hg-MIF (as summarized by ${ }^{20}$ ) (Supplementary Fig. 3). Oddnumber Hg-MIF has also been observed in ocean sediments deposited since the Mesoproterozoic ${ }^{16,17,23,36-38}$. Specifically, coastal sediments tend to have negative odd-number Hg-MIF due to a major contribution from terrestrial $\mathrm{Hg}$ sources, while offshore sediments mainly show positive odd-number Hg-MIF due to a major contribution from atmospheric $\mathrm{Hg}$ (II) deposition $^{37}$. In the sediments we examined, the upper and lower intervals of the section show positive $\Delta^{199} \mathrm{Hg}$ values, whereas organic-rich mudstones within the interval from $\sim 830$ to $840 \mathrm{~m}$ depth are characterized by slightly negative Hg-MIF or zero $\Delta{ }^{199} \mathrm{Hg}$ values from -0.2 to $-0.01 \%$ (with $2 \sigma$ of $0.07 \%$ ) (Fig. 1).

Significant changes in even-number $\mathrm{Hg}$ isotopes, with $\Delta^{200} \mathrm{Hg}$ values from -0.1 to $+0.3 \%$ (Fig. 1), are also preserved throughout this section. Unlike odd-number $\mathrm{Hg}$-MIF, large MIF of even-number $\mathrm{Hg}$ isotopes has only been observed in modern atmospheric samples. For instance, rain samples, which mainly contain oxidized $\mathrm{Hg}(\mathrm{II})$ species, are characterized by positive $\Delta^{200} \mathrm{Hg}$ signals, whereas gaseous $\mathrm{Hg}(0)$ shows negative $\Delta^{200} \mathrm{Hg}$ signals ${ }^{32-35}$ (Supplementary Fig. 3). For this reason, seawater and ocean sediments sometimes have slightly positive $\Delta^{200} \mathrm{Hg}$ due to wet deposition of atmospheric $\mathrm{Hg}(\mathrm{II})^{17,31,37}$. Photoreduction of aqueous $\mathrm{Hg}(\mathrm{II})$ does not induce evennumbered Hg-MIF, so these anomalies are thought to be produced exclusively during photooxidation of gaseous $\mathrm{Hg}(0)$ in the atmosphere $21,32,34$. The majority of our studied section shows positive $\Delta^{200} \mathrm{Hg}$ values, although the organic-rich mudstones within the interval from $\sim 830$ to $840 \mathrm{~m}$ depth are characterized by near zero $\Delta^{200} \mathrm{Hg}$ values, from -0.04 to $+0.08 \%$ (with $2 \sigma$ of $0.06 \%$ ) (Fig. 1 ). 

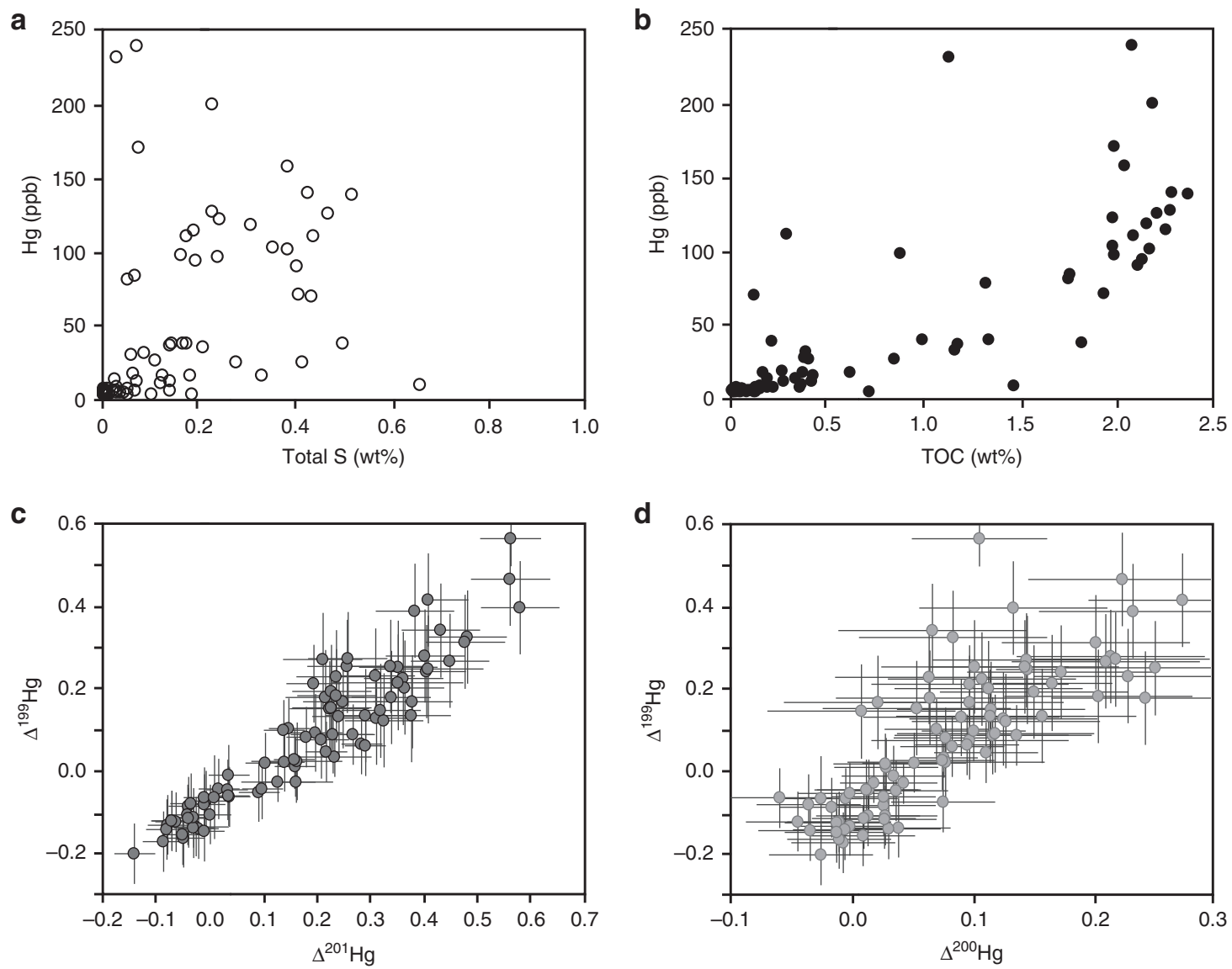

Fig. 2 Cross plots of geochemical data. Uncertainties on $\mathrm{Hg}$ isotope data correspond to the larger value of either the measurement uncertainty of replicate digests of MESS-2 or the uncertainty of repeated measurements of UM-Almadén; analytical uncertainties for additional data are encompassed within each individual data point. These plots demonstrate a lack of correlation between $\mathrm{Hg}$ (ppb) and total sulfur content (S wt\%) (a), and generally positive correlations between $\mathrm{Hg}(\mathrm{ppb})$ and total organic carbon (TOC, wt\%) (b), $\Delta^{199} \mathrm{Hg}$ and $\Delta^{201} \mathrm{Hg}$ (both in \%o) (c), and $\Delta^{199} \mathrm{Hg}$ and $\Delta^{200} \mathrm{Hg}($ both in $\%$ ) (d).

Late Archean $\mathrm{Hg}$ isotope mass-independent fractionation. The positive Hg-MIF measured throughout the majority of this section record some of the highest $\Delta^{199} \mathrm{Hg}$ values (up to $0.6 \%$ ) and $\Delta^{200} \mathrm{Hg}$ values (up to $0.3 \%$ ) reported in ocean sediments to date $16,17,22,36-38$ (Fig. 3). Since $\Delta^{200} \mathrm{Hg}$ anomalies are exclusively produced in the atmosphere, the strong correlation between $\Delta^{199} \mathrm{Hg}$ and $\Delta^{200} \mathrm{Hg}$ observed in these samples (Fig. 2d) also implies that both signals were mainly formed in the atmosphere. The large magnitude of these $\mathrm{Hg}$-MIF values suggests that $\mathrm{Hg}$ (II) photoreduction and $\operatorname{Hg}(0)$ photooxidation were more intense when these sediments were deposited, likely due to the lack of significant levels of molecular oxygen in the Late Archean atmosphere. This follows because molecular oxygen is required for ozone formation, and ozone blocks ultraviolet radiation that can drive photochemical reactions near the Earth's surface.

While atmospheric deposition of $\mathrm{Hg}(0)$ carrying negative $\mathrm{Hg}$ MIF signals could also have occurred during this time, the generally positive $\Delta^{199} \mathrm{Hg}$ and $\Delta^{200} \mathrm{Hg}$ values in our samples suggest that atmospheric $\mathrm{Hg}$ (II) deposition was the dominant input of $\mathrm{Hg}$ to these sediments. Once deposited in the oceans, $\mathrm{Hg}$ (II) carrying positive $\mathrm{Hg}$-MIF signals would subsequently have been scavenged by organic particles and transported to the seafloor. $\mathrm{Hg}$ (II) photoreduction could also have occurred in surface seawater, contributing to the shift in the $\Delta^{199} \mathrm{Hg}$ values; however, the magnitude of this shift is generally limited in the present-day oceans, because photoreduction of $\mathrm{Hg}$ in oceans is suppressed by excessive chloride ligands which form strong complexes with $\mathrm{Hg}(\mathrm{II})^{39}$. A recent study in the modern ocean demonstrated no significant difference in $\Delta^{199} \mathrm{Hg}$ in seawater at different depths, suggesting that $\mathrm{Hg}$ (II) photoreduction does not significantly alter water column $\Delta^{199} \mathrm{Hg}$ values, at least in the modern oceans ${ }^{31}$.

During laboratory experiments, photochemical oxidation or reduction of $\mathrm{Hg}$ generally produces trends in $\mathrm{Hg}-\mathrm{MDF}$ that are correlated with Hg-MIF. For example, a correlation between $\delta^{202} \mathrm{Hg}$ and $\Delta^{199} \mathrm{Hg}$, with $\Delta^{199} \mathrm{Hg} / \delta^{202} \mathrm{Hg}$ of $\sim 1.2$, is generally associated with photochemical reduction reactions induced in the laboratory ${ }^{15-17,23,40,41}$. The $\delta^{202} \mathrm{Hg}$ values in our study are not correlated with either $\Delta^{199} \mathrm{Hg}$ or $\Delta^{200} \mathrm{Hg}$; however, we would not expect any correlation to be preserved in natural samples, given that (as above) numerous physical, chemical, and biological processes occurring in the water column and sediments can produce MDF that would shift the sedimentary $\delta^{202} \mathrm{Hg}$ without affecting the $\Delta^{199} \mathrm{Hg}$ or $\Delta^{200} \mathrm{Hg}$. This assertion is supported by previous studies of ocean sediments, which have also shown no correlation between $\delta^{202} \mathrm{Hg}$ and $\Delta^{199} \mathrm{Hg}^{15-17,23,40,41}$ (Fig. 4). This comparison with previously published data also demonstrates that the majority of our data appear to occupy a different field in $\delta^{202} \mathrm{Hg}$ versus $\Delta^{199} \mathrm{Hg}$ space than marine sediments from more recent time periods in Earth history, pointing to some fundamental difference(s) in $\mathrm{Hg}$-MIF generation in anoxic versus oxygenated atmospheres. A detailed examination of the potential mechanisms for this difference is beyond the scope of the current study, but should provide a critical target for future work.

Interestingly, enhanced $\mathrm{Hg}$ concentrations within the organicrich mudstone interval from $\sim 830$ to $840 \mathrm{~m}$ depth in core GKF01 

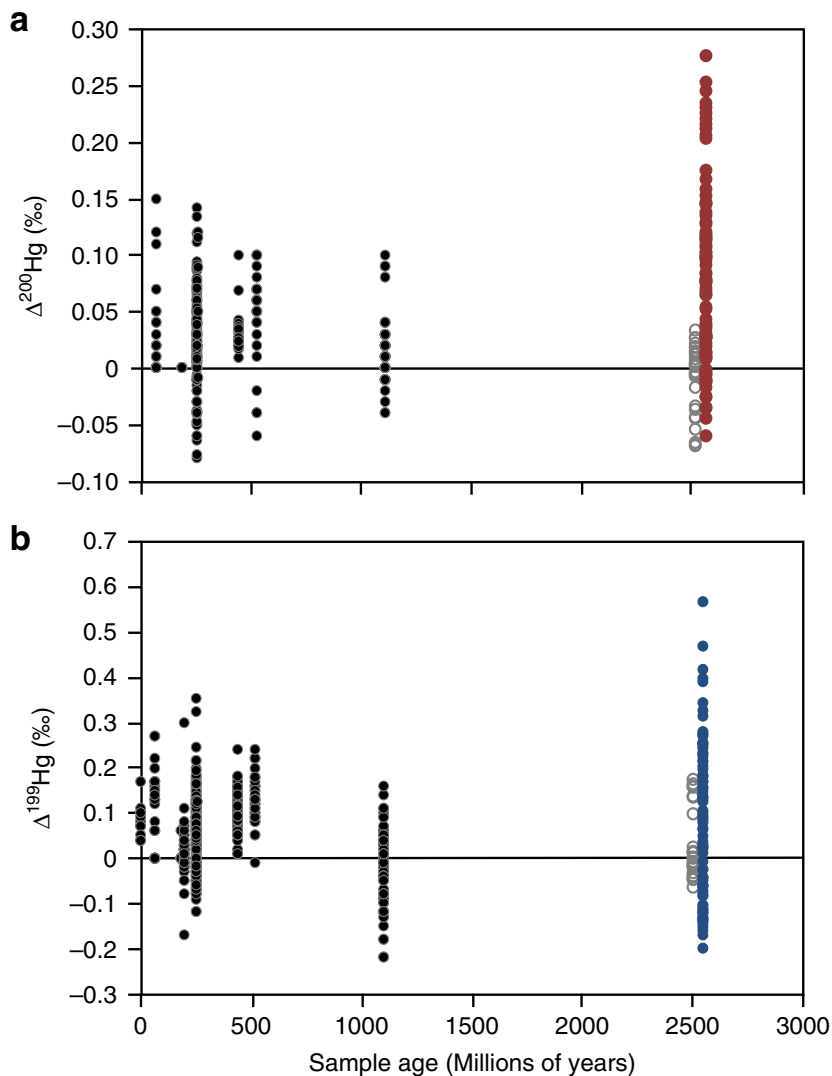

Fig. 3 Temporal plot of mercury isotope data from the rock record. These include $\Delta^{200} \mathrm{Hg}$ (in \%o, a) and $\Delta^{199} \mathrm{Hg}$ (in \%o, b). Our data are shown as red dots (for $\Delta^{200} \mathrm{Hg}$ ) and blue dots (for $\Delta^{199} \mathrm{Hg}$ ). Previously published Proterozoic and Phanerozoic data (shown as black dots) are compiled from ${ }^{15-18,20,23,36,38,41,55-57}$. The only previously published Hg-MIF data from Archean sediments (shown as gray open circles) were from the Mt McRae shale ${ }^{20}$, which have been controversially associated with transient atmospheric oxygen before the $\mathrm{GOE}^{5}$.

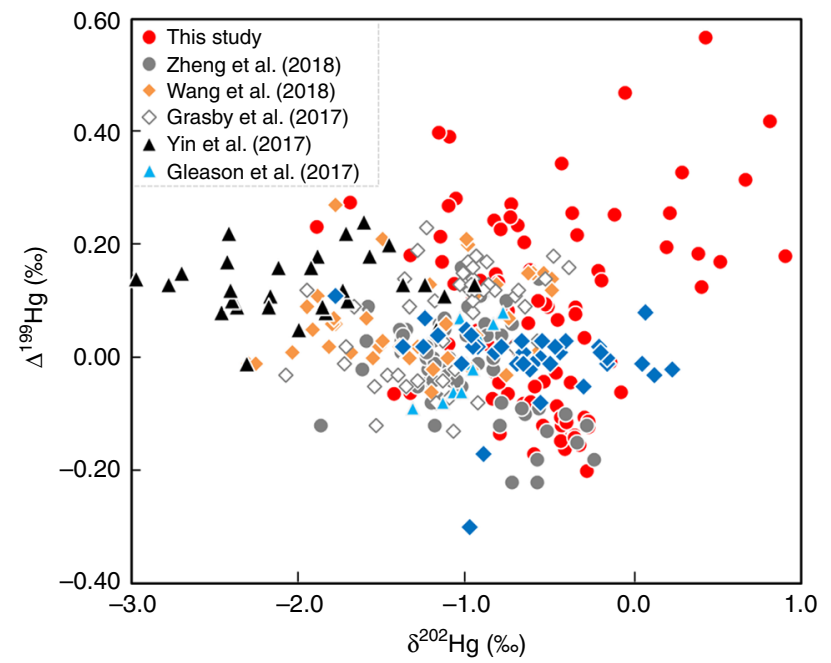

Fig. 4 Cross plots of mercury isotope data from marine sediments. These include $\delta^{202} \mathrm{Hg}$ versus $\Delta^{199} \mathrm{Hg}$ from late Late Archean sediments (our data) compared with Late Mesoproterozoic shales from Africa ${ }^{23}$, Early Cambrian shales from China ${ }^{17}$, end-Permian sediments from China ${ }^{16,41}$, end-Triassic shelf sediments from North America 58 , and Eocene shales from the Arctic $\operatorname{Basin}^{40}$. are associated with significant changes in both $\Delta^{199} \mathrm{Hg}$ and $\Delta^{200} \mathrm{Hg}$, to zero or slightly negative $\mathrm{Hg}$-MIF values. As mentioned above, negative $\Delta^{199} \mathrm{Hg}$ and $\Delta^{200} \mathrm{Hg}$ values are generally characteristic of gaseous $\mathrm{Hg}(0)$. Runoff of vegetation and terrestrial particles, which adsorb gaseous $\mathrm{Hg}(0)$, are the main contributors of negative $\mathrm{Hg}$-MIF to modern sediments; however, these sources would have been negligible in the Archean due to the absence of vegetation and significant terrestrial soils ${ }^{42}$. Consequently, we suggest that the following scenarios could be responsible for shifting $\Delta^{199} \mathrm{Hg}$ and $\Delta^{200} \mathrm{Hg}$ values over this interval: enhanced sequestration of atmospheric $\operatorname{Hg}(0)$ to the sediments by thiols and sulfides that were enriched in the surface ocean as a result of photic zone euxinia (e.g., as proposed for the Mesoproterozoic ${ }^{23}$ ) (scenario 1); enhanced terrestrial input of geogenic $\mathrm{Hg}$ with no MIF signals (scenario 2); enhanced volcanic input of $\mathrm{Hg}$ with no MIF signals (scenario 3); or changes in production or deposition of $\mathrm{Hg}$-MIF associated with changes in atmospheric chemistry (scenario 4 ).

As noted above, the lack of evidence for water column euxinia $^{26,43}$ (Supplementary Fig. 2) along with a lack of correlation between $\mathrm{Hg}$-MIF and total sulfur content (Fig. 2a) suggests that enhanced sequestration by thiols is unlikely, allowing the elimination of scenario 1. Enhanced terrestrial influx of $\mathrm{Hg}$, as invoked in scenario 2, is inconsistent with lithological and elemental evidence. Namely, the facies change towards more organic carbon-rich mudstones suggests a move toward a more distal depositional environment ${ }^{24}$, which is inconsistent with additional terrestrial runoff from land. Elemental proxy data also support basinal deepening and a general decrease in terrestrial detritus (Supplementary Fig. 4). Given that changes in $\mathrm{Si} / \mathrm{Al}$ are generally interpreted to imply a change in terrestrial provenance (excluding biological Si-cycling), if we take $\mathrm{Si} / \mathrm{Al}$ as a broad indicator, the decrease in $\mathrm{Ti}$ and $\mathrm{Zr}$ at the expense of $\mathrm{Al}$ (as shown in Supplementary Fig. 4) is consistent with deeper water deposition and entrainment of heavy minerals (rutile and zircon) in nearshore settings. The increase in K/Al further suggests the increased significance of clays in deeper water settings. We also note that limited data from the similar organicrich mudstone unit up-core do not feature similar $\mathrm{Hg}$ isotope systematics, further arguing against a simple facies control on this signature.

An increase in volcanic $\mathrm{Hg}$ input across this interval (scenario 3) cannot explain the change in $\mathrm{Hg}$-MIF values either. $\mathrm{Hg}$ concentrations and $\mathrm{Hg} / \mathrm{TOC}$ remain generally low in these strata, suggesting that even if there were volcanism it did not greatly perturb the $\mathrm{Hg}$ cycle. Discrete peaks in $\mathrm{Hg}$ levels and $\mathrm{Hg} / \mathrm{TOC}$ could indicate periodically enhanced volcanic $\mathrm{Hg}$ emissions ${ }^{22}$, but REE patterns from this interval further suggest that volcanism was not pervasive ${ }^{24}$. Regardless, the lack of correlation between the peak in $\mathrm{Hg}$ /TOC and the change in Hg-MIF means that even if the $\mathrm{Hg} / \mathrm{TOC}$ peak was volcanically derived, the volcanism was not solely responsible for the $\mathrm{Hg}$ cycle perturbation.

Given the lack of evidence for enhanced euxinia or terrestrial input, and only discrete evidence for enhanced volcanism, we suggest that the changes in Hg-MIF within this interval were largely due to a change in atmospheric chemistry (scenario 4). In particular, the slightly negative $\Delta^{199} \mathrm{Hg}$ values at the bottom of this interval (Fig. 1) support the increased importance of atmospheric $\mathrm{Hg}(0)$ as a source of $\mathrm{Hg}$ to the oceans. Since only $\mathrm{Hg}$ (II) is particle reactive and rains out into the oceans, this change would have required the atmospheric $\operatorname{Hg}(0)$ pool to be oxidized and deposited from the atmosphere without further changes to $\mathrm{Hg}$ isotope values. The presence of large magnitude SMIF throughout this section (Supplementary Fig. 2) precludes the involvement of oxygen or ozone as a major component of the atmosphere ${ }^{9}$. In addition, $\mathrm{Hg}(0)$ is mainly oxidized by halogens 
(iodine and bromine), even in the modern, oxygenated atmosphere $^{44}$. This trend would therefore imply that some additional change in reducing atmospheric chemistry occurred.

Previously published multi-proxy geochemical data from this section provide further insight into atmospheric chemistry during this time interval. Similar to $\Delta^{199} \mathrm{Hg}$ and $\Delta^{200} \mathrm{Hg}$, S-MIF values in sedimentary pyrite and $\delta^{13} \mathrm{C}$ values in organic carbon show large changes across the same part of this section (Fig. 1). In particular, $\Delta^{36} \mathrm{~S} / \Delta^{33} \mathrm{~S}$ ratios change from a background of approximately -0.9 to much steeper slopes of approximately $-1.5^{26}$ in correlation with a negative excursion in $\delta^{13} \mathrm{C}_{\text {org }}$ (Fig. 1; Supplementary Fig. 2). Similar changes in $\Delta^{36} S / \Delta^{33} S$ and $\delta^{13} C_{\text {org }}$ have been documented in multiple horizons within the GKF01 core, all independent of facies changes (Supplementary Fig. 2; see also Fig. S3 from ref. ${ }^{26}$ ). These trends have now been correlated between five cores from South Africa and Western Australia ${ }^{45}$, and are shown to be conserved at the grain scale (Supplementary Fig. 2; ref. ${ }^{46}$ ). The consistency of these changes in S-MIF signals across multiple spatial scales has been used to argue for a global atmospheric driver ${ }^{6,26,47}$. The largest $\Delta^{200} \mathrm{Hg}$ values we measure are correlated with the most negative $\Delta^{36} \mathrm{~S} / \Delta^{33} \mathrm{~S}$ ratios in this section (Supplementary Fig. 5), suggesting a common mechanism.

Coupled changes in S-MIF and $\delta^{13} \mathrm{C}_{\text {org }}$ in the Late Archean have previously been interpreted to reflect changes in atmospheric chemistry and transparency induced by formation of a hydrocarbon-rich haze at high atmospheric $\mathrm{CH}_{4}: \mathrm{CO}_{2}{ }^{6,26,45}$. Photochemical models of S-MIF formation in the Archean atmosphere have further demonstrated the ability of organic haze to change atmospheric S-MIF signatures ${ }^{6,26,47}$. The changes in Hg-MIF across this interval could also be explained by organic haze formation, since organic aerosols could have induced deposition of gaseous $\mathrm{Hg}(0)$ via oxidation and sorption. Elemental $\mathrm{Hg}(0)$ can be oxidized and scavenged by lowmolecular-weight organic compounds in the atmosphere, as demonstrated by consistent $\mathrm{Hg} / \mathrm{TOC}$ ratios measured in modern precipitation $^{48}$. Thus oxidation and sequestration of gaseous $\mathrm{Hg}$ (0) by organic particles in the haze could have transported these negative Hg-MIF signals to the oceans and sediments, consistent with the trends in $\mathrm{Hg}$ and TOC described above.

The continued presence of organic haze could have limited further $\mathrm{Hg}$-MIF formation throughout the rest of this interval by limiting or changing the penetration of ultraviolet radiation and inhibiting the photochemical reactions of $\mathrm{Hg}$, as the negative $\mathrm{Hg}$ MIF-bearing $\mathrm{Hg}(0)$ was progressively stripped from the atmosphere. Previous studies have proposed that even-number $\mathrm{Hg}$ MIF mainly forms in the tropopause. After photooxidation, $\mathrm{Hg}$ (II) carrying the positive $\Delta^{200} \mathrm{Hg}$ anomaly could be transported downward by stratosphere-to-troposphere incursion to the surface. In fact, even-number Hg-MIF of rain samples worldwide displays a general increase with latitude, confirming the upper atmosphere as the possible origin ${ }^{49}$. Photochemical models of the Archean atmosphere suggest that hydrocarbon haze would have formed very high in the stratosphere ${ }^{50,51}$, and therefore provides a viable alternative mechanism to shield even-number Hg-MIF formation in the tropopause, as well as odd-number Hg-MIF formation in the surface oceans and atmosphere 32,34 .

The scenario we propose for producing the observed trends in Hg-MIF is summarized in Fig. 5. During the Late Archean (Fig. 5a), intense photoreduction and photooxidation in the absence of ozone produced particle-reactive $\mathrm{Hg}$ (II) with large positive $\Delta^{199} \mathrm{Hg}$ and $\Delta^{200} \mathrm{Hg}$ that were deposited into the oceans and subsequently the sediments. These processes left the atmospheric $\mathrm{Hg}(0)$ pool with negative $\Delta^{199} \mathrm{Hg}$ and $\Delta^{200} \mathrm{Hg}$, similar to the modern environment. During the hazy period (Fig. 5b), the negative $\mathrm{Hg}$-MIF-bearing atmospheric $\mathrm{Hg}(0)$ was oxidized to $\mathrm{Hg}$
(II) by low-molecular-weight organic compounds and deposited to the ocean, which then diluted the positive MIF signals in seawater, and caused negative shifts of $\Delta^{199} \mathrm{Hg}$ and $\Delta^{200} \mathrm{Hg}$ in seawater and sediments. Decreased atmospheric transparency could have hindered further Hg-MIF production, until the haze cleared and background Hg-MIF production resumed.

These striking observations provide definitive support for $\mathrm{Hg}$ MIF as a powerful paleoatmospheric proxy in marine sediments. We have shown that these data respond differently than S-MIF to changes in the chemistry of reducing atmospheres, and can thus provide independent, complementary constraints on the composition and evolution of atmospheric chemistry in the Archean. Combined, these records point to a dynamic Late Archean atmosphere on the run-up to the GOE, with at least two distinct atmospheric states responding to both volcanic emissions and methane production. Notably, these data support earlier suggestions of a vital role for the anaerobic biosphere and biogeochemical methane cycling in the evolution of Earth's early atmosphere.

\section{Methods}

Elemental analyses. Samples from core GKF01, through the $\sim 2.6-2.5 \mathrm{Ga}$ Griqualand West Basin, South Africa ${ }^{24}$, were collected from the National Core Library at Donkerhoek (Pretoria, South Africa) (Supplementary Fig. 1), as described by Izon et al. ${ }^{26}$ Major elemental abundance data (listed in Supplementary Data 2) were determined by X-ray florescence analysis at the University of St Andrews, Scotland, following the protocol outlined by ${ }^{52}$. Here, aliquots of homogenized samples were pre-combusted at $1000{ }^{\circ} \mathrm{C}$ in ceramic crucibles to remove their volatile constituents, thus allowing loss on ignition to be calculated. The volatilefree sample residues were fused using a mixed lithium tetraborate $\left(\mathrm{Li}_{2} \mathrm{~B}_{4} \mathrm{O}_{7} ; 20 \%\right)$ and lithium metaborate $\left(\mathrm{LiBO}_{2} ; 80 \%\right)$ flux in $\mathrm{Pt}-\mathrm{Au}$ crucibles. Ammonium iodide $\left(\mathrm{NH}_{4} \mathrm{I}\right)$ was used as a releasing agent. These fused samples were analyzed on a Spectro Xepos HE, with a 50 Watt end-window X-ray tube to excite the samples and a $30 \mathrm{~mm}^{2}$ Si-drift detector with Peltier cooling, providing spectral resolution $(\mathrm{FWHM}) \leq 155 \mathrm{eV}$ at Mn K-alpha. Replicate analysis of a suite of standards (GSR1-152 6, SBC-1, OU-8, OU-6, and SD0-1) produced values that were inseparable from their certified values, equating to relative uncertainties of $<3 \%$.

Trace element analyses (listed in Supplementary Data 3) were also performed at the University of St Andrews. Here, $0.25 \mathrm{~g}$ aliquots of pre-combusted residues were mixed and fused with $1.25 \mathrm{~g}$ of an equal mixture of $\mathrm{Li}_{2} \mathrm{~B}_{4} \mathrm{O}_{7}$ and $\mathrm{LiBO}_{2}$ in acidcleaned Pt-Au crucibles. The resultant glass bead, after dissolution in $5 \%$ (vol/vol) ultra-pure nitric acid, was manipulated and prepared for analysis using a Thermo $\mathrm{X}$ series2 ICP-MS. Standardization was achieved via matrix-matched synthetic standards, while drift was corrected by internal normalization after Re, Ge, and $\mathrm{Rh}$ doping. Alongside unknowns, the same suite of major element standards was processed in an identical manner to the unknowns, producing data typically better than $10 \%$ of their certified values.

Mercury isotope analyses. Total $\mathrm{Hg}$ concentrations (summarized in Supplementary Data 1) were determined by the RA-915+ Hg analyzer coupled with the PYRO-915+ attachment (Lumex, Russia), at Institute of Geochemistry, Chinese Academy of Sciences (IGCAS). Recoveries for standard reference materials GSS-5 $(n=3)$ and MESS-2 $(n=3)$ were between 94 and 112\%, and coefficients of variation (triplicate analyses) were $<8 \%$.

At IGCAS, a double-stage tube furnace coupled with $40 \%$ anti aqua regia $\left(\mathrm{HNO}_{3} / \mathrm{HCl}=2 / 1, \mathrm{v} / \mathrm{v}\right)$ trapping solutions was used for $\mathrm{Hg}$ preconcentration, prior to isotope analysis. This combustion system was developed and validated in a previous study ${ }^{53}$. For samples with high $\mathrm{Hg}$ concentrations $\left(>25 \mathrm{ng} \mathrm{g}^{-1}\right)$, an acid digestion method using aqua regia $\left(\mathrm{HNO}_{3} / \mathrm{HCl}=1 / 3, \mathrm{v} / \mathrm{v}\right)$ was used in parallel to the combustion method ${ }^{54}$. MESS-2 was included in both sample preparation methods. All the solutions were diluted to $\sim 0.5 \mathrm{ng} \mathrm{mL}^{-1} \mathrm{Hg}$ in $10-20 \%(\mathrm{v} / \mathrm{v}$ ) acids using $18.2 \mathrm{M} \Omega \mathrm{cm}$ water, and analyzed by Neptune Plus multiple collector inductively coupled plasma mass spectrometer (Thermo Electron Corp, Bremen, Germany) at the University Research Facility in Chemical and Environmental Analysis (UCEA) in the Hong Kong Polytechnic University, following our recently published method ${ }^{54}$. The instrument was equipped with the HGX-200 system and an Aridus II Desolvating Nebulizer System (CETAC Technologies, USA) for Hg and $\mathrm{Tl}$ introduction, respectively. NIST SRM $997 \mathrm{Tl}$ standard $\left(50 \mathrm{ng} \mathrm{mL}^{-1}\right)$ was used as an internal standard for simultaneous instrumental mass bias correction of $\mathrm{Hg}$. The instrument was tuned using the NIST SRM $3133 \mathrm{Hg}$ standard solution for maximum intensity of ${ }^{202} \mathrm{Hg}$ signal using Ar gas flows, torch position, and lenses. The sensitivity for ${ }^{202} \mathrm{Hg}$ was $1.8 \mathrm{~V}$ per $\mathrm{ng} \mathrm{mL}^{-1} \mathrm{Hg}$. Total $\mathrm{Hg}$ in sample solutions was monitored by MC-ICP-MS using ${ }^{202} \mathrm{Hg}$ signals. The signals for ${ }^{202} \mathrm{Hg}$ were $<0.01 \mathrm{~V}$ for acid blanks of both sample preparation methods, corresponding to $<1 \%$ of that in sample solutions. The Hg recoveries of MESS-2 were $96-110 \%$ for the combustion method $(n=9)$, similar to that yielded by the acid digestion method $(94-111 \%, n=3)$. Total $\mathrm{Hg}$ values of the samples estimated by ${ }^{202} \mathrm{Hg}$ signals were 


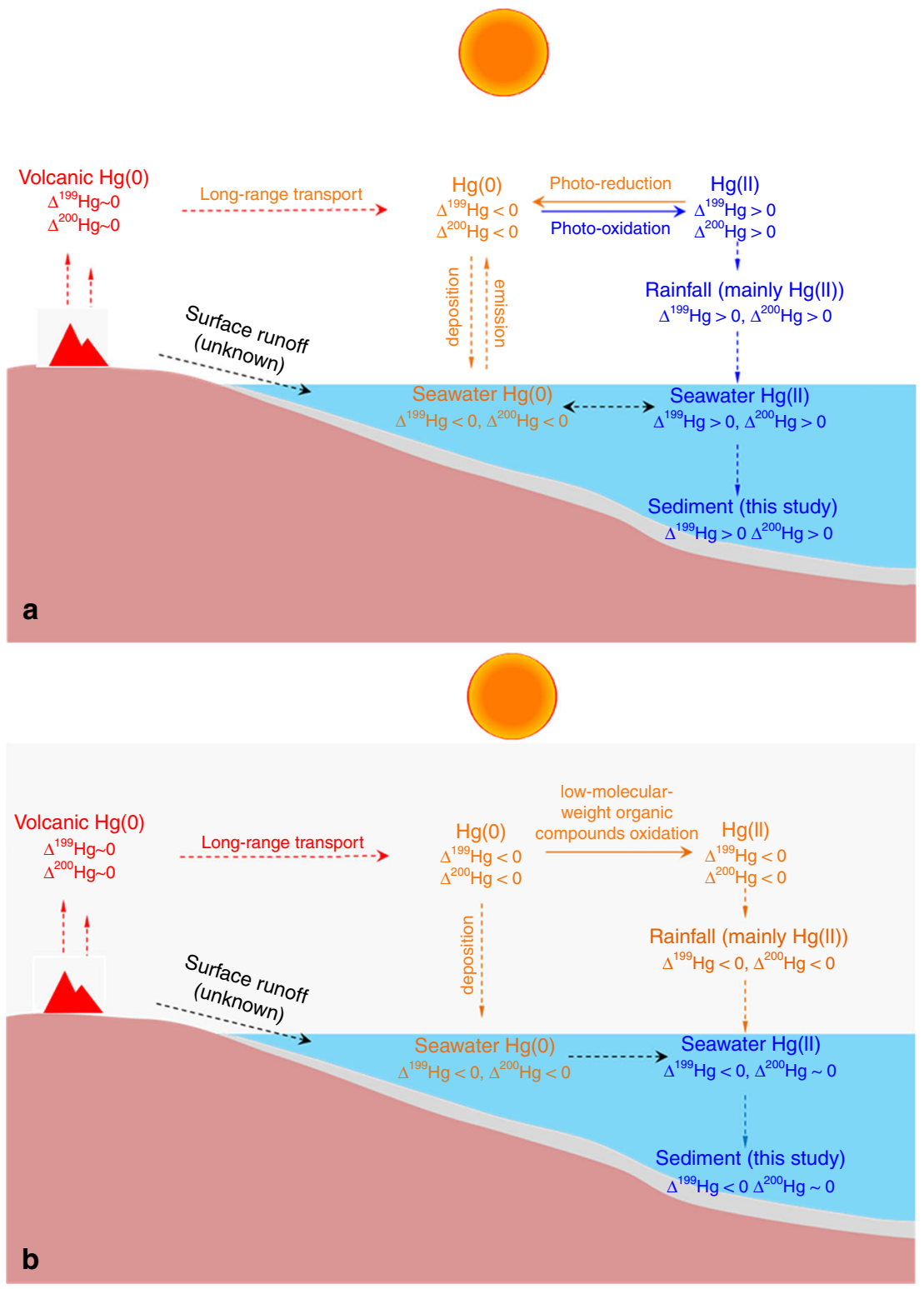

Fig. 5 Proposed scenarios for observed mercury isotope fractionation trends. a Intense photochemical reactions in the absence of an ozone layer lead to the production of large $\mathrm{Hg}$-MIF in the Archean atmosphere. The red color represents volcanic $\mathrm{Hg}(0)$, which has been the primary source of $\mathrm{Hg}$ to the Earth surface over geologic time. This volcanic $\mathrm{Hg}(0)$ is characterized by $\Delta^{199} \mathrm{Hg} \sim 0 \%$ and $\Delta^{200} \mathrm{Hg} \sim 0 \%$, and can undergo long-range transport in the atmosphere. Atmospheric $\mathrm{Hg}(0)$ was oxidized to gaseous $\mathrm{Hg}(\mathrm{II})$, and a fraction of that $\mathrm{Hg}(\mathrm{II})$ was photoreduced back to $\mathrm{Hg}(0)$. These photochemical processes produced gaseous $\mathrm{Hg}(0)$ with negative $\Delta^{199} \mathrm{Hg}$ and $\Delta^{200} \mathrm{Hg}$ values, and gaseous $\mathrm{Hg}(\mathrm{II})$ with positive $\Delta^{199} \mathrm{Hg}$ and $\Delta^{200} \mathrm{Hg}$ values. The orange color represents the deposition of gaseous $\mathrm{Hg}(0)$ to ocean surface and the reemission to the atmosphere. The light blue color represents the deposition of gaseous $\mathrm{Hg}(\mathrm{II})$ through precipitation, the scavenging of seawater $\mathrm{Hg}$ (mainly precipitated $\mathrm{Hg}(\mathrm{II})$ ) by organic particles, and the burial of organic-bound $\mathrm{Hg}$ with mainly positive $\Delta^{199} \mathrm{Hg}$ and $\Delta^{200} \mathrm{Hg}$ signals in marine sediments. $\mathbf{b}$ In the presence of a hydrocarbon haze, nearly all $\mathrm{Hg}(0)$ was oxidized by low molecular weight organic compounds before deposition, scavenging, and burial. The red color represents volcanic $\mathrm{Hg}(0)$, which was mixed with background atmospheric $\mathrm{Hg}(0)$ carrying negative $\Delta^{199} \mathrm{Hg}$ and $\Delta^{200} \mathrm{Hg}$ values. The orange color represents nearly complete oxidation of $\mathrm{Hg}(0)$ to $\mathrm{Hg}(\mathrm{II})$, and therefore the deposited $\mathrm{Hg}(\mathrm{II})$ is characterized by negative $\Delta^{199} \mathrm{Hg}$ and $\Delta^{200} \mathrm{Hg}$ values. The light blue color represents the mixing of the deposited atmospheric $\mathrm{Hg}(\mathrm{II})$ with seawater $\mathrm{Hg}$ that is characterized with positive $\Delta^{199} \mathrm{Hg}$ and $\Delta^{200} \mathrm{Hg}$ values. The scavenging and the burial of these two forms of $\mathrm{Hg}$ produced marine sediments with slightly negative $\Delta^{199} \mathrm{Hg}$ and near zero $\Delta^{200} \mathrm{Hg}$ signals.

$92-119 \%$ to that measured by RA-915+ Hg analyzer. The larger variability of samples compared with MESS-2 (Supplementary Table 1) is potentially due to heterogeneities in $\mathrm{Hg}$ concentration of sample powders.

NIST SRM $3133 \mathrm{Hg}$ standard solutions and UM-Almadén secondary standard solutions were prepared, with matrix and concentration matched within $10 \%$ to sample dilutions. Standard sample bracketing was performed with NIST SRM 3133 $\mathrm{Hg}$ standard solutions. Mercury isotope were reported following convention ${ }^{19}$ such as mass-dependent fractionation was expressed in $\delta^{202} \mathrm{Hg}$ notation in units of permil (\%) referenced to the NIST SRM $3133 \mathrm{Hg}$ standard (analyzed before and after each sample):

$$
\delta^{202} \mathrm{Hg}(\% \mathrm{o})=\left[\left({ }^{202} \mathrm{Hg} /{ }^{198} \mathrm{Hg} \text { sample }\right) /\left({ }^{202} \mathrm{Hg} /{ }^{198} \mathrm{Hg}_{\text {standard }}\right)-1\right] \times 1000
$$

Mass-independent fractionation is reported in $\Delta$ notation $\left(\Delta^{\mathrm{xxx}} H \mathrm{Hg}\right)$, which describes difference between the measured $\delta^{\mathrm{xx}} \mathrm{Hg}$ and the theoretically predicted 
$\delta^{\mathrm{xxx}} \mathrm{Hg}$ value, in units of permil (\%o), using the following formula:

$$
\Delta^{\mathrm{xxx}} \mathrm{Hg} \approx \delta^{\mathrm{xxx}} \mathrm{Hg}-\delta^{202} \mathrm{Hg} \times \beta,
$$

$\beta$ is equal to 0.2520 for ${ }^{199} \mathrm{Hg}, 0.5024$ for ${ }^{200} \mathrm{Hg}$, and 0.7520 for ${ }^{201} \mathrm{Hg}^{19}$.

Analytical uncertainty was estimated based on the replication of the UM-

Almadén secondary standard solutions and full procedural analyses of MESS-2. As shown in Supplementary Table 1, results of UM-Almadén are consistent with recommended values ${ }^{19}$, and MESS-2 processed with the acid digestion and the oven combustion procedure showed identical isotope compositions which are consistent with recommended values ${ }^{16,17}$, thereby validating the methods. Uncertainties reported in this study correspond to the larger value of either the measurement uncertainty of replicate digests of MESS-2 or the uncertainty of repeated measurements of UM-Almadén.

\section{Data availability}

All new data from this study are available in the Supplementary Data files; previously published data are available from the referenced works.

Received: 16 July 2019; Accepted: 11 March 2020;

Published online: 06 April 2020

\section{References}

1. Farquhar, J., Bao, H. M. \& Thiemens, M. Atmospheric influence of Earth's earliest sulfur cycle. Science 289, 756-758 (2000).

2. Luo, G. et al. Rapid oxygenation of Earth's atmosphere 2.33 billion years ago. Sci. Adv. 2, 1-9 (2016)

3. Gumsley, A. P. et al. Timing and tempo of the Great Oxidation Event. Proc. Natl Acad. Sci. 114, 1811-1816 (2017).

4. Philippot, P. et al. Globally asynchronous sulphur isotope signals require redefinition of the Great Oxidation Event. Nat. Commun. 9, 2245 (2018).

5. Anbar, A. D. et al. A whiff of oxygen before the great oxidation event? Geochim. Cosmochim. Acta 71, A24-A24 (2007).

6. Zerkle, A. L., Claire, M. W., Domagal-Goldman, S. D., Farquhar, J. \& Poulton, S. W. A bistable organic-rich atmosphere on the Neoarchean Earth. Nat. Geosci. 5, 359-363 (2012).

7. Koehler, M. C., Buick, R., Kipp, M. A., Stueken, E. E. \& Zaloumis, J. Transient surface ocean oxygenation recorded in the $\sim 2.66$-Ga Jeerinah Formation, Australia. Proc. Natl Acad. Sci. 2018, 1-6 (2018).

8. Crowe, S. A. et al. Atmospheric oxygen three billion years ago. Nature 501, 535-538 (2013).

9. Pavlov, A. A. \& Kasting, J. F. Mass-independent fractionation of sulfur isotopes in Archean sediments: strong evidence for an anoxic Archean atmosphere. Astrobiology 2, 27-41 (2002).

10. Schroeder, W. H. \& Munthe, J. Atmospheric mercury-an overview. Atmos. Environ. 32, 809-822 (1998).

11. Bergquist, B. A. Mercury, volcanism, and mass extinctions. Proc. Natl Acad. Sci. 114, 8675-8677 (2017)

12. Enrico, M. et al. Atmospheric mercury transfer to peat bogs dominated by gaseous elemental mercury dry deposition. Environ. Sci. Technol. 50, 2405-2412 (2016).

13. Obrist, D. et al. Tundra uptake of atmospheric elemental mercury drives Arctic mercury pollution. Nature 547, 201 (2017).

14. Selin, N. E. Global biogeochemical cycling of mercury: a review. Annu. Rev Enviorn. Resour. 34, 43-63 (2009).

15. Thibodoeau, A. M. et al. Mercury anomalies and the timing of biotic recovery following the end-Triassic mass extinction. Nat. Commun. 7, 11147 (2016).

16. Grasby, S. E. et al. Isotopic signatures of mercury contamination in latest Permian oceans. Geology 45, 55-58 (2016)

17. Yin, R., Xu, L. \& Lehmann, B. Anomalous mercury enrichment in Early Cambrian black shales of South China: mercury isotopes indicate a seawater source. Chem. Geol. 467, 159-167 (2017).

18. Shen, J. et al. Evidence for a prolonged Permian-Triassic extinction interval from global marine mercury records. Nat. Commun. 10, 1563 (2019).

19. Bergquist, B. A. \& Blum, J. D. Mass-dependent and -independent fractionation of $\mathrm{Hg}$ isotopes by photoreduction in aquatic systems. Science 318, 417-420 (2007).

20. Blum, J. D., Sherman, L. S. \& Johnson, M. W. Mercury isotopes in earth and environmental sciences. Ann. Revi.Earth Pl. Sci. 42, 249-269 (2014).

21. Sun, G., Sommar, J. \& Feng, X. Mass-dependent and independent fractionation of mercury isotopes during gas-phase oxidation of elemental mercury vapor by atomic $\mathrm{Cl}$ and Br. Environ. Sci. Technol. 50, 9232-9241 (2016).

22. Grasby, S. E., Them II, T. R., Chen, Z., Yin, R. \& Ardakani, O. H. Mercury as a proxy for volcanic emmisions in the geologic record. Earth-Sci. Rev. 196, 102880 (2019).
23. Zheng, W., Gilleaudeau, G. J., Kah, L. C. \& Anbar, A. Mercury isotope signatures record photic zone euxinia in the Mesoproterozoic ocean. Proc. Natl Acad. Sci. 115, 10594-10599 (2018).

24. Schröder, S., Lacassie, J. P. \& Beukes, N. J. Stratigraphic and geochemical framework of the Aguoron drill cores, Transvaal Supergroup (NeoarcheanPaleoproterozoic, South Africa). S. Afri. J. Geol. 109, 23-54 (2006).

25. Altermann, W. \& Nelson, D. R. Sedimentation rates, basin analysis and regional correlations of three Neoarchean and Paleoproterozoic sub-basins of the Kaapvaal Cratoninferred from precise U-Pb zircon ages from volcaniclastic sediments. Sediment. Geol. 120, 225-256 (1998).

26. Izon, G. et al. Biological regulation of atmospheric chemistry en route to planetary oxygenation. Proc. Natl Acad. Sci. 114, 2571-2579 (2017)

27. Bergquist, B. A. \& Blum, J. D. The odds and evens of mercury isotopes: applications of mass-dependent and mass-independent isotope fractionation. Elements 5, 353-357 (2009).

28. Blum, J. D. Handbook of Environmental Isotope Geochemistry 229-245 (Springer, 2012)

29. Sonke, J. E. A global model of mass independent mercury stable isotope fractionation. Geochim. Cosmochim. Acta 75, 4577-4590 (2011).

30. Sun, R. et al. Modelling the mercury stable isotope distribution of Earth surface reservoirs: implications for global Hg cycling. Geochim. Cosmochim. Acta 246, 156-173 (2019).

31. Štrok, M., Baya, P. A. \& Hintelmann, H. The mercury isotope composition of Arctic coastal seawater. CR Geosci. 347, 368-376 (2015).

32. Chen, J. B., Hintelmann, H., Feng, X. B. \& Dimock, B. Unusual fractionation of both odd and even mercury isotopes in precipitation from Peterborough, ON, Canada. Geochim. Cosmochim. Acta 90, 33-46 (2012).

33. Demers, J. D., Blum, J. D. \& Zak, D. R. Mercury isotopes in a forested ecosystem: Implications for air-surface exchange dynamics and the global mercury cycle. Global Biogeochem. Cycles 27, 222-238 (2013).

34. Gratz, L. E., Keeler, G. J. \& Blum, J. D. Isotopic composition and fractionation of mercury in Great Lakes precipitation and ambient air. Environ. Sci. Technol. 44, 7764-7770 (2010).

35. Rolison, J. M., Landing, W. M. \& Luke, W. Isotopic composition of speciesspecific atmospheric Hg in a coastal environmenta. Chem. Geol. 336, 37-49 (2013).

36. Gehrke, G. E., Blum, J. D. \& Meyers, P. A. The geochemical behavior and isotopic compositions of $\mathrm{Hg}$ in mid-Pleistocene western Mediterranean sapropel. Geochim. Cosmochim. Acta 73, 1651-1665 (2009).

37. Yin, R. et al. Mercury inputs to Chinese marginal seas - impact of industrialization and development of China. J. Geophys. Res. 123, 5599-5611 (2018).

38. Them, I. I. T. R. et al. Terrestrial sources as the primary delivery mechanism of mercury to the oceans across the Toarcian Oceanic Anoxic Event (Early Jurassic). Earth Planet. Sci. Lett. 507, 62-72 (2019).

39. Yamamoto, M. Stimulation of elemental mercury oxidation in the presence of choride ion in aquatic environments. Chemosphere 32, 1217-1224 (1996).

40. Gleason, J. D. et al. Sources and cycling of mercury in the paleo Arctic Ocean from $\mathrm{Hg}$ stable isotope variations in Eocene and Quaternary sediments. Geochim. Cosmochim. Acta 197, 245-262 (2017).

41. Wang, X. et al. Mercury anomalies across the end Permian mass extinction in South China from shallow and deep water depositional environments. Earth Planet. Sci. Lett. 496, 159-167 (2018).

42. Ponomarenko, A. G. Early evolutionary stages of soil ecosystems. Biol. Bull. Revi. 5, 267-279 (2015).

43. Kendall, B. et al. Pervasive oxygenation along late Archean ocean margins. Nat. Geosci. 3, 647-652 (2010).

44. Seigneur, C. \& Lohman, K. Effect of bromine chemistry on the atmospheric mercury cycle. J. Geophys. Res. 113, D22309 (2008).

45. Izon, G. et al. Multiple oscillations in Neoarchean atmospheric chemistry. Earth Planet. Sci. Lett. 431, 264-273 (2015).

46. Farquhar, J. et al. Pathways for Neoarchean pyrite formation constrained by mass-independent sulfur isotopes. Proc.Natl .Acad. Sci. 110, 17638-17643 (2013).

47. Claire, M. W. et al. Modeling the signature of sulfur mass-independent fractionation produced in the Archean atmosphere. Geochim.Cosmochim. Acta 141, 365-380 (2014).

48. Akerblom, S., Meili, M. \& Bishop, K. Organic matter in rain: an overlooked influence on mercury deposition. Environ. Sci.Technol. Letters 2, 128-132 (2015).

49. Cai, H. \& Chen, J. Mass-independent fractionation of even mercury isotopes. Scie. Bull. 61, 116-124 (2016)

50. Pavlov, A. A., Kasting, J. F., Eigenbrode, J. L. \& Freeman, K. H. Organic haze in Earth's early atmosphere: Source of low-C-13 Late Archean kerogens? Geology 29, 1003-1006 (2001).

51. Arney, G. et al. The pale orange dot: the spectrum and habitability of hazy Archean Earth. Astrobiology 16, 1-27 (2016). 
52. Mettam, C. et al. High-frequency fluctuations in redox conditions during the latest Permian mass extinction. Palaeogeogr. Palaeoclimatol. Palaeoecol. 485, 210-223 (2017).

53. Fu, X., Heimburger, L. E. \& Sonke, J. E. Collection of atmospheric gaseous mercury for stable isotope analysis using iodine- and chlorine-impregnated activated carbon traps. J. Anal. At. Spectrom. 29, 841-852 (2014).

54. Geng, H., Yin, R. \& Li, X. An optimized protocol of high precision measurements of $\mathrm{Hg}$ isotopic compositions in samples with low concentrations of Hg using MC-ICP-MS. J. Anal. At. Spectrom. 33, 1932-1940 (2018).

55. Gong, Q. et al. Mercury spikes suggest volcanic driver of the OrdovicianSilurian mass extinction. Sci. Rep. 7, 5304 (2017).

56. Wang, X. et al. Global mercury cycle during the end-Permian mass extinction and subsequent Early Triassic recovery. Earth Planet. Sci. Lett. 513, 144-155 (2019).

57. Sial, A. N., Chen, J. \& Lacerda, L. D. Mercury enrichment and Hg isotopes in Cretaceous-Paleogene boundary successions: Links to volcanism and palaeoenvironmental impacts. Cretac. Res. 66, 60-81 (2016).

58. Thibodoeau, A. M. et al. Mercury anomalies and the timing of biotic recovery following the end-Triassic mass extinction. Nat. Commun. 7, 11747 (2016).

\section{Acknowledgements}

This work was funded by a Natural Environment Research Council (NERC) Fellowship NE/H016805/2 and Standard Grant NE/J023485/2 (to A.L.Z.). R.Y. was funded by the Chinese Academy of Sciences through the Hundred Talent Plan. G.J.I. recognizes continued support from R. Summons under the auspices of the Simons Collaboration on the Origin of Life. We thank J. Kirschvink, J. Grotzinger, A. Knoll, and the Agouron Institute for organizing and funding the Agouron Drilling Project, and the Council for Geoscience in South Africa, specifically those at the National Core Library in Donkerhoek, for facilitating access to the core materials. A.L.Z. thanks M. Claire and the St Andrews MIFIn Atmospheres group for stimulating discussions. We also thank J. Farquhar and two anonymous reviewers, whose comments greatly improved the paper.

\section{Author contributions}

A.L.Z. and R.Y. designed research; A.L.Z. and G.J.I. collected samples; R.Y., C.C., and G.J.I. performed analyses; X.D.L. contributed analytical tools and data discussion;
S.E.G. provided conceptual advice; A.L.Z. and R.Y. wrote the paper, with input from all coauthors.

\section{Competing interests}

The authors declare no competing interests.

\section{Additional information}

Supplementary information is available for this paper at https://doi.org/10.1038/s41467020-15495-3.

Correspondence and requests for materials should be addressed to A.L.Z. or R.Y.

Peer review information Nature Communications thanks Timothy Lyons and the other, anonymous, reviewer(s) for their contribution to the peer review of this work. Peer reviewer reports are available.

Reprints and permission information is available at http://www.nature.com/reprints

Publisher's note Springer Nature remains neutral with regard to jurisdictional claims in published maps and institutional affiliations.

cc Open Access This article is licensed under a Creative Commons Attribution 4.0 International License, which permits use, sharing, adaptation, distribution and reproduction in any medium or format, as long as you give appropriate credit to the original author(s) and the source, provide a link to the Creative Commons license, and indicate if changes were made. The images or other third party material in this article are included in the article's Creative Commons license, unless indicated otherwise in a credit line to the material. If material is not included in the article's Creative Commons license and your intended use is not permitted by statutory regulation or exceeds the permitted use, you will need to obtain permission directly from the copyright holder. To view a copy of this license, visit http://creativecommons.org/ licenses/by/4.0/.

(C) The Author(s) 2020 